\title{
Association of C-reactive protein, tumor necrosis factor-alpha, and interleukin-6 with chronic kidney disease
}

Belinda T. Lee', Faheemuddin A. Ahmed ${ }^{1}$, L. Lee Hamm,2,3, Federico J. Teran' ${ }^{1}$, Chung-Shiuan Chen ${ }^{4}$, Yanxi Liư ${ }^{4}$ Kamal Shah", Nader Rifai ${ }^{5}$, Vecihi Batuman ${ }^{1,3}$, Eric E. Simon ${ }^{1,3}$, Jiang He $\mathrm{e}^{1,2,4}$ and Jing Chen ${ }^{1,24^{*}}$

\begin{abstract}
Background: We studied the association of inflammatory biomarkers including C-reactive protein (CRP), tumor necrosis factor-alpha (TNF-a), and interleukin-6 (IL-6) with chronic kidney disease (CKD).

Methods: We conducted a case-control study among 201 CKD patients and 201 community-based controls in the greater New Orleans area. CKD was defined as estimated-glomerular filtration rate (eGFR) $<60 \mathrm{~mL} / \mathrm{min} / 1.73 \mathrm{~m}^{2}$ or albuminuria $\geq 30 \mathrm{mg} / 24-\mathrm{h}$. Serum CRP, TNF-a, and IL-6 were measured using standard methods. Multivariable regression models were used to examine associations between the inflammatory biomarkers and CKD adjusting for important CKD risk factors, history of cardiovascular disease, and use of antihypertensive, antidiabetic, and lipid-lowering agents and aspirin.

Results: The multivariable-adjusted medians (interquartile-range) were $2.91(1.47,5.24) \mathrm{mg} / \mathrm{L}$ in patients with CKD vs. $1.91(0.99,3.79) \mathrm{mg} / \mathrm{L}$ in controls without $C K D$ ( $p=0.39$ for group difference) for CRP; $1.86(1.51,2.63) \mathrm{pg} / \mathrm{mL}$ vs. $1.26(1.01,1.98) \mathrm{pg} / \mathrm{mL}(\mathrm{p}<0.0001)$ for TNF-a; and $2.53(1.49,4.42) \mathrm{pg} / \mathrm{mL}$ vs. $1.39(0.95,2.15) \mathrm{pg} / \mathrm{mL}(\mathrm{p}=0.04)$ for IL-6, respectively. Compared to the lowest tertile, the highest tertile of TNF-a (OR 7.1, $95 \% \mathrm{Cl} 3.2$ to 15.5) and IL-6 (OR 2.5, $95 \%$ Cl 1.1 to 5.5) were significantly associated with higher odds of CKD in multivariable-adjusted models. Additionally, higher TNF- $a$ and IL-6 were independently and significantly associated with lower eGFR and higher albuminuria.
\end{abstract}

Conclusions: Our data suggest that TNF- $a$ and IL-6, but not CRP, are associated with the prevalence and severity of CKD, independent from established CKD risk factors, history of cardiovascular disease, and use of antihypertensive, antidiabetic, and lipid-lowering agents and aspirin.

Keywords: C-reactive protein, Choric kidney disease, Inflammation, Interleukin-6, Tumor necrosis factor-alpha

\section{Background}

Chronic kidney disease (CKD) is highly prevalent worldwide and a major risk factor for end-stage renal disease (ESRD), cardiovascular disease (CVD), and premature death [1]. Systemic inflammation has been associated with increased risk of CVD and mortality in patients with CKD [2]. For example, C-reactive protein (CRP), an acute phase reactant, is associated with all-cause and CVD mortality in patients with ESRD [3-7]. Tumor necrosis factor-alpha

\footnotetext{
* Correspondence: jchen@tulane.edu

'Department of Medicine, Tulane University School of Medicine, New

Orleans, LA, USA

${ }^{2}$ Hypertension and Renal Center of Excellence, Tulane University School of

Medicine, New Orleans, LA, USA

Full list of author information is available at the end of the article
}

(TNF- $\alpha$ ) and interleukin-6 (IL-6), key cytokines that mediate both acute and chronic inflammation, are associated with CVD morbidity and mortality in the general population [8-10] and in predialysis and dialysis patients $[11,12]$. However, several epidemiological studies have reported inconsistent findings on the associations of CRP, TNF- $\alpha$, IL- 6 , and CKD. For instance, Gupta and colleagues reported that CRP was inversely associated with estimated glomerular filtration rate (eGFR) but not associated with urine albumin-to-creatinine ratio in the Chronic Renal Insufficiency Cohort (CRIC) Study [13]. Upadhyay and colleagues reported that multivariable-adjusted means of TNF- $\alpha$ and IL-6, but not CRP, were significantly elevated among patients with CKD in the Framingham Offspring 
cohort [14]. In addition, it remains uncertain if the association of CRP, TNF- $\alpha$, and IL- 6 with CKD is independent of traditional CKD risk factors, history of CVD, and use of antihypertensive, antidiabetic, and lipid-lowering agents and aspirin.

The objective of this case-control study is to investigate the association of circulating CRP, TNF- $\alpha$, and IL- 6 with CKD after adjusting for multiple important risk factors, including current treatment for hypertension, hyperlipidemia, diabetes, and CVD. In addition, we examine the association between circulating CRP, TNF- $\alpha$, and IL- 6 with CKD severity, measured by eGFR and urinary albumin excretion.

\section{Methods}

\section{Study participants}

We recruited 201 CKD patients and 201 controls without CKD in the greater New Orleans, Louisiana area from 2007 to 2010 . CKD patients were age 21 to 74 years and recruited from nephrology and internal medicine clinics in the study area. CKD was defined as eGFR $<60 \mathrm{ml} / \mathrm{min} / 1.73 \mathrm{~m}^{2}$ or the presence of albuminuria ( $\geq 30 \mathrm{mg} / 24-\mathrm{h}$ ) for three or more months. Patients with acute kidney injury were excluded. In addition, patients were excluded if they had a history of chronic dialysis, kidney transplant, immunotherapy in the past six months, chemotherapy within the past two years, or current clinical trial participation that may have an impact on CKD. Additional exclusion criteria were history of HIV or AIDS and inability or unwillingness to give informed consent. Control participants were recruited through mass mailings to residents aged 21-74 years living in the same area according to zip code.

Tulane University Internal Review Board approved this study, and written informed consent was obtained at the screening visit from all study participants. This study adheres to the Declaration of Helsinki.

\section{Study measurements}

A standard questionnaire was administered by trained staff at a clinical visit to obtain demographic information, lifestyle risk factors (including cigarette smoking and alcohol ingestion), self-reported history of CVD, diabetes, hypercholesterolemia, and hypertension, as well as the use of antihypertensive, lipid-lowering, and antidiabetic medications.

Three blood pressure (BP) measurements were obtained at a clinical visit by trained and certified staff according to a common protocol adapted from procedures recommended by the American Heart Association [15]. A standard mercury sphygmomanometer was used, and one of four cuff sizes (pediatric, regular adult, large, or thigh) was chosen on the basis of the circumference of the participant's arm. Body height and weight were obtained by trained staff and used to calculate body mass index $\left(\mathrm{BMI}=\right.$ weight in $\mathrm{kg} /$ height $^{2}$ in $\left.\mathrm{m}\right)$ and body surface area using Mosteller's formula [(weight in $\mathrm{kg} \times$ height in $\mathrm{cm}) / 3600]^{1 / 2}[16]$.

An overnight fasting blood sample was collected to measure plasma glucose, serum creatinine, cholesterol, and triglycerides. A 24-h urinary sample was collected to measure creatinine and albumin. Serum cholesterol and triglyceride levels were assayed using an enzymatic procedure on the Hitachi 902 automatic analyzer (Roche Diagnostics, Indianapolis, IN, USA). Serum glucose was measured using a hexokinase enzymatic method (Roche Diagnostics, Indianapolis, IN, USA). Serum creatinine was measured using the Roche enzymatic method (RocheHitachi P-Module instrument with Roche Creatininase Plus assay, Hoffman-La Roche, Basel, Switzerland). Urinary concentrations of albumin and creatinine were measured with a DCA 2000 Analyzer (Bayer AG, Leverkusen, Germany). eGFR was estimated from serum creatinine, sex, age, and race using the CKD-Epi equation [17].

Serum levels of CRP were measured by a highsensitivity latex-enhanced immunonephelometric assay (Roche Diagnostics, Indianapolis, IN). The assay has a sensitivity of $0.02 \mathrm{mg} / \mathrm{L}$ and an intra-assay coefficient of variation $(\mathrm{CV})$ of $<1.0 \%$ and an inter-assay $\mathrm{CV}$ of $3.7 \%$. Serum levels of IL- 6 were measured by a commercially available ELISA (Quantikine HS human IL-6 Immunoassay kit, R\&D System, Minneapolis, MN). The detectable limit for IL-6 is $0.039 \mathrm{pg} / \mathrm{mL}$, the intra-assay CV is from $6.9 \%$ to $7.8 \%$, and the inter-assay $\mathrm{CV}$ is from $6.5 \%$ to $9.6 \%$. Serum TNF- $\alpha$ levels were measured by a commercially available ELISA (Quantikine HS human TNF- $\alpha$ Immunoassay kit, R \& D Systems, Minneapolis, $\mathrm{MN})$. The detectable limit for TNF- $\alpha$ is $0.12 \mathrm{pg} / \mathrm{mL}$, the intra-assay $\mathrm{CV}$ is from $5.3 \%$ to $8.8 \%$, and the interassay $\mathrm{CV}$ is from $10.8 \%$ to $16.7 \%$.

\section{Statistical analysis}

Medians and interquartile ranges for serum CRP, IL-6, and TNF- $\alpha$ were calculated for CKD patients and controls, and the Mann-Whitney $U$ test was used to test differences in the unadjusted medians. Quantile regression was used to obtain adjusted medians (interquartile ranges) and the Wald test was used to test differences in the adjusted medians between CKD patients and controls [18]. These analyses were adjusted for age, gender, race, high-school education, physical activity, current cigarette smoking, weekly alcohol drinking, body-mass index, LDL-cholesterol, plasma glucose, systolic blood pressure, history of CVD, use of antihypertensive, antidiabetic, and lipid-lowering agents, and aspirin.

Multivariate logistic regression was used to obtain adjusted odds ratios comparing the higher tertiles of CRP, IL-6, and TNF- $\alpha$ levels to the lowest tertile between CKD patients and controls. Serum tertile levels were 
Table 1 Characteristics of the Participants by Chronic Kidney Disease Status

\begin{tabular}{|c|c|c|c|}
\hline Variables & $\begin{array}{l}\text { CKD patients } \\
(\mathrm{n}=201)\end{array}$ & $\begin{array}{l}\text { Non-CKD controls } \\
(n=201)\end{array}$ & $\begin{array}{l}P \text {-value fo } \\
\text { difference }\end{array}$ \\
\hline Age, yrs & $55.9 \pm 9.9$ & $52.5 \pm 10.0$ & 0.0007 \\
\hline Male, \% & 55.2 & 45.3 & 0.05 \\
\hline Blacks, $\%$ & 60.7 & 51.2 & 0.06 \\
\hline $\begin{array}{l}\text { High school } \\
\text { education, \% }\end{array}$ & 58.5 & 81.6 & $<0.0001$ \\
\hline $\begin{array}{l}\text { Current cigarette } \\
\text { smoking, \% }\end{array}$ & 53.7 & 48.8 & 0.32 \\
\hline $\begin{array}{l}\text { Weekly alcohol } \\
\text { drinking, \% }\end{array}$ & 27.9 & 59.2 & $<0.0001$ \\
\hline $\begin{array}{l}\text { Regular physical } \\
\text { activity }{ }^{a} \%\end{array}$ & 53.0 & 72.9 & $<0.0001$ \\
\hline History of CVD, \% & 43.7 & 7.0 & $<0.0001$ \\
\hline $\begin{array}{l}\text { History of } \\
\text { hypertension, \% }\end{array}$ & 88.1 & 23.9 & $<0.0001$ \\
\hline History of diabetes, $\%$ & 49.3 & 5.5 & $<0.0001$ \\
\hline $\begin{array}{l}\text { History of } \\
\text { hypercholesterolemia, \% }\end{array}$ & 65.7 & 30.9 & $<0.0001$ \\
\hline $\begin{array}{l}\text { Body-mass index, } \\
\mathrm{kg} / \mathrm{m}^{2}\end{array}$ & $32.2 \pm 7.8$ & $28.9 \pm 6.4$ & $<0.0001$ \\
\hline $\begin{array}{l}\text { Systolic blood } \\
\text { pressure, } \mathrm{mmHg}\end{array}$ & $132.2 \pm 21.0$ & $122.0 \pm 14.7$ & $<0.0001$ \\
\hline $\begin{array}{l}\text { Diastolic blood } \\
\text { pressure, } \mathrm{mmHg}\end{array}$ & $77.2 \pm 13.5$ & $77.6 \pm 9.4$ & 0.77 \\
\hline $\begin{array}{l}\text { Plasma glucose, } \\
\mathrm{mg} / \mathrm{dL}\end{array}$ & $119.9 \pm 46.7$ & $103.4 \pm 35.4$ & $<0.0001$ \\
\hline $\begin{array}{l}\text { LDL-cholesterol, } \\
\mathrm{mg} / \mathrm{dL}\end{array}$ & $103.3 \pm 45.9$ & $118.2 \pm 30.2$ & $<0.0001$ \\
\hline $\begin{array}{l}\mathrm{HDL} \text {-cholesterol, } \\
\mathrm{mg} / \mathrm{dL}\end{array}$ & $50.3 \pm 15.6$ & $57.7 \pm 18.0$ & $<0.0001$ \\
\hline $\mathrm{eGFR}, \mathrm{mL} / \mathrm{min} / 1.73 \mathrm{~m}^{2}$ & $43.3 \pm 19.9$ & $96.7 \pm 16.8$ & $<0.0001$ \\
\hline $\begin{array}{l}\text { Urinary albumin, } \\
\mathrm{mg} / 24-\mathrm{h}\end{array}$ & $\begin{array}{l}74.5(12.3 \\
417.4)\end{array}$ & $5.9(4.1,11.4)$ & $<0.0001$ \\
\hline
\end{tabular}

Mean \pm standard deviation, percentage, or median (inter-quartile range) $L D L$ low-density lipoprotein; $H D L$ high-density lipoprotein; $e G F R$ estimatedglomerular filtration rate; and CVD cardiovascular disease

${ }^{a}$ Moderate or heavy physical activity at least twice per week defined based upon measurements in the control group. In addition, multivariable linear regression was used to examine the association of serum levels of CRP, IL-6, and TNF- $\alpha$ with eGFR and albuminuria after adjustment for the previously mentioned covariates. Log transformations were used for CRP, IL-6, TNF- $\alpha$, and urinary albumin levels, because they were not normally distributed. We did not impute missing data. All analyses were performed using SAS version 9.2 statistical software (Cary, NC).

Our study was designed to have an $80 \%$ statistical power to detect an odds ratio of 1.77 at a 2 -sided significance level of 0.05 when the cases and controls were compared by the tertile of biomarkers. In addition, we have an $80 \%$ statistical power to detect a mean difference of 0.3 standard deviations of biomarkers between the cases and controls at a 2 -sided significance level of 0.05 .

\section{Results}

The general characteristics of study participants by CKD status are presented in Table 1. Patients with CKD had a mean eGFR of $43.4 \mathrm{~mL} / \mathrm{min} / 1.73 \mathrm{~m}^{2}$ compared to $96.7 \mathrm{~mL} / \mathrm{min} / 1.73 \mathrm{~m}^{2}$ among controls without CKD. Among 201 CKD patients, 5 were stage-1, 33 stage-2, 104 stage-3, 49 stage-4, and 10 stage-5. Median urinary albumin excretion was $74.5 \mathrm{mg} / 24 \mathrm{~h}$ in CKD patients and $5.9 \mathrm{mg} / 24 \mathrm{~h}$ in controls. Those with CKD were older, less educated, and less likely to drink alcohol or engage in regular physical activity compared to those without CKD. In addition, they were more likely to have a history of CVD, hypertension, diabetes, and hypercholesterolemia. Mean BMI, systolic BP, and serum glucose levels were significantly higher, while LDL- and HDLcholesterol were lower in CKD patients compared to controls.

The median serum levels of CRP, IL- 6 , and TNF- $\alpha$ were significantly higher in patients with CKD compared to controls. After adjusting for important covariables, the medians of IL- 6 and TNF-a, but not CRP, remained significantly higher (Table 2).

Table 2 Medians and inter-quartile range of inflammatory biomarkers according to chronic kidney disease status

\begin{tabular}{|c|c|c|c|c|c|c|}
\hline \multirow{2}{*}{$\begin{array}{l}\text { Inflammatory } \\
\text { Biomarkers }\end{array}$} & \multicolumn{3}{|c|}{ Unadjusted median (IQR) } & \multicolumn{3}{|c|}{ Multivariable-adjusted median (IQR) ${ }^{a}$} \\
\hline & $\begin{array}{l}\text { CKD patients } \\
(\mathrm{n}=201)\end{array}$ & $\begin{array}{l}\text { Non-CKD controls } \\
(n=201)\end{array}$ & $P$-value for difference & $\begin{array}{l}\text { CKD patients } \\
(\mathrm{n}=201)\end{array}$ & $\begin{array}{l}\text { Non-CKD controls } \\
(n=201)\end{array}$ & $P$-value for difference \\
\hline CRP, mg/L (IQR) & $2.80(1.13,5.61)$ & $1.49(0.75,3.65)$ & $<0.0001$ & $2.91(1.47,5.24)$ & $1.91(0.99,3.79)$ & 0.39 \\
\hline TNF-a, pg/mL (IQR) & $1.82(1.5,2.51)$ & $1.27(0.99,1.81)$ & $<0.0001$ & $1.86(1.51,2.63)$ & $1.26(1.01,1.98)$ & $<0.0001$ \\
\hline IL-6, pg/mL (IQR) & $2.46(1.32,4.54)$ & $1.24(0.88,2.2)$ & $<0.0001$ & $2.53(1.49,4.42)$ & $1.39(0.95,2.15)$ & 0.04 \\
\hline
\end{tabular}

$\mathrm{IQR}=$ inter-quartile range; $\mathrm{CRP}=\mathrm{C}$-reactive protein; TNF- $\mathrm{a}=$ tumor necrosis factor alpha; IL- $6=$ interleukin 6

${ }^{a}$ Adjusted for age, gender, race, high-school education, physical activity, current cigarette smoking, weekly alcohol drinking, body-mass index, LDL-cholesterol, plasma glucose, systolic blood pressure, history of cardiovascular disease, antihypertensive treatment, antidiabetic treatment, lipid lowering treatment, and aspirin use 
Table 3 Odds ratios of chronic kidney disease associated with the higher tertile compared to the lowest tertiles of inflammatory biomarkers

\begin{tabular}{|c|c|c|c|c|}
\hline & \multicolumn{2}{|c|}{$\begin{array}{l}\text { Age, gender, and } \\
\text { race-adjusted }\end{array}$} & \multicolumn{2}{|c|}{ Multivariable-adjusted $^{a}$} \\
\hline & OR $(95 \% \mathrm{Cl})$ & $\begin{array}{l}P \text {-value } \\
\text { for trend }\end{array}$ & $\mathrm{OR}(95 \% \mathrm{Cl})$ & $\begin{array}{l}P \text {-value } \\
\text { for trend }\end{array}$ \\
\hline \multicolumn{5}{|c|}{ CRP ( mg/L) } \\
\hline$\leq 1.1$ & 1.0 (ref) & 0.0002 & 1.0 (ref) & 0.15 \\
\hline$>1.1-3.3$ & $1.3(0.8-2.2)$ & & $1.2(0.6-2.5)$ & \\
\hline$>3.3$ & $2.7(1.6-4.1)$ & & $1.8(0.8-3.9)$ & \\
\hline \multicolumn{5}{|c|}{ TNF-a (ng/mL) } \\
\hline$\leq 1.3$ & 1.0 (ref) & $<0.0001$ & 1.0 (ref) & $<0.0001$ \\
\hline$>1.3-1.9$ & $6.6(3.7-11.7)$ & & $5.8(2.7-12.7)$ & \\
\hline$>1.9$ & $7.8(4.4-13.8)$ & & $7.1(3.2-15.5)$ & \\
\hline \multicolumn{5}{|c|}{ IL-6 ( $\mathrm{gg} / \mathrm{mL})$} \\
\hline$\leq 1.2$ & 1.0 (ref) & $<0.0001$ & 1.0 (ref) & 0.02 \\
\hline$>1.2-2.6$ & $1.7(1-2.8)$ & & $1.1(0.5-2.3)$ & \\
\hline$>2.6$ & $5.0(2.8-8.6)$ & & $2.5(1.1-5.5)$ & \\
\hline
\end{tabular}

$\mathrm{Cl}$ confidence interval; CRP C-reactive protein; TNF- $a$ tumor necrosis factor alpha; IL-6 interleukin 6

${ }^{a}$ Adjusted for age, gender, race, high-school education, physical activity, current cigarette smoking, weekly alcohol drinking, body-mass index, LDLcholesterol, plasma glucose, systolic blood pressure, history of cardiovascular disease, antihypertensive treatment, antidiabetic treatment, lipid lowering treatment, and aspirin use

The multivariate-adjusted odds ratios (95\% confidence intervals) of CKD comparing the higher two tertiles to the lowest tertile of the serum inflammatory biomarker levels from the multivariate-adjusted logistic regression analyses are presented in Table 3. The higher levels of TNF- $\alpha$ and IL-6, but not CRP, were significantly associated with odds of CKD after adjusting for multiple confounding factors.

In multivariable-adjusted linear regression analyses, serum levels of TNF- $\alpha$ and IL- 6 were inversely and significantly related to eGFR and positively related to urinary albumin excretion (Table 4). On the other hand, serum CRP level was not significantly associated with either eGFR or urine albumin excretion.

\section{Discussion}

The present study shows that inflammatory biomarkers TNF- $\alpha$ and IL- 6 are significantly elevated in patients with CKD compared to controls without CKD. In addition, TNF- $\alpha$ and IL- 6 are significantly and positively associated with the severity of CKD, measured by eGFR and urinary albumin excretion. These associations are independent of established risk factors for CKD, history of CVD, and use of antihypertensive, antidiabetic, and lipid-lowering agents, as well as aspirin. In this study, serum level of CRP is not independently associated with CKD.

CRP is a well-recognized risk factor for CVD and mortality in the general population as well as in patients with ESRD $[3-7,19]$. However, our study indicates that circulating CRP level was not significantly elevated in pre-dialysis CKD patients after accounting for established CKD risk factors, history of CVD, and use of antihypertensive, antidiabetic, and lipid-lowering agents, and aspirin. This finding is consistent with several previous reports [14, 20-22]. In addition, our study reports that serum CRP was not associated with eGFR or albuminuria in multiple linear regression models. In contrast, a previous cross-sectional epidemiological study suggested that CRP was associated with eGFR but not urine albumin-to-creatinine ratio among patients with CKD [13]. However, two longitudinal epidemiologic studies also suggested that CRP was not associated with the risk of developing CKD [23, 24]. Taken together, these findings suggest that CRP is not an independent risk factor for CKD.

Our study shows that circulating TNF- $\alpha$ and IL-6 levels are significantly higher in CKD patients compared to controls and the levels of TNF- $\alpha$ and IL- 6 are independently associated with the severity of CKD. These findings are consistent with those of previous large epidemiological studies $[13,14]$. The longitudinal study by Shankar et al. also suggested that TNF- $\alpha$ receptor 2 and IL-6 levels were positively associated with the risk of developing CKD [23]. However, it is possible that albuminuria selectively activates cytokines and elevates TNF- $\alpha$

Table 4 Multivariable-adjusted regression coefficients (95\% confidence intervals) of estimated-glomerular filtration rate and urinary albumin associated with a one standard deviation difference in inflammatory biomarkers

\begin{tabular}{|c|c|c|c|c|}
\hline \multirow{2}{*}{$\begin{array}{l}\text { Inflammatory } \\
\text { biomarkers (SD) }\end{array}$} & \multicolumn{2}{|c|}{ Estimated-glomerular filtration rate, $\mathrm{mL} / \mathrm{min} / 1.73 \mathrm{~m}^{2}$} & \multicolumn{2}{|c|}{ Log (urinary albumin, mg/24-h) } \\
\hline & $\beta(95 \% \mathrm{Cl})$ & $P$-value & $\beta(95 \% \mathrm{Cl})$ & $P$-value \\
\hline CRP (Log, 1.33 mg/L) & $-1.27(-4.11$ to 1.58$)$ & 0.38 & $0.11(-0.08$ to 0.29$)$ & 0.27 \\
\hline TNF-a (Log,0.69 ng/mL) & $-5.02(-7.56$ to -2.47$)$ & 0.0001 & 0.27 (0.1 to 0.44$)$ & 0.002 \\
\hline IL-6 ( Log, 0.9 ng/mL) & $-4.69(-7.65$ to -1.73$)$ & 0.0028 & 0.35 (0.16 to 0.54$)$ & 0.0003 \\
\hline
\end{tabular}

Adjusted for age, gender, race, high-school education, physical activity, current cigarette smoking, weekly alcohol drinking, body mass index, LDL-cholesterol, plasma glucose, systolic blood pressure, history of cardiovascular disease, antihypertensive treatment, antidiabetic treatment, lipid lowering treatment, and aspirin use

SD standard deviation; log log-transformation; Cl confidence interval; CRP C-reactive protein; TNF- $a$ tumor necrosis factor alpha; IL-6 interleukin 6 
and IL- 6 levels. In addition, there may be decreased clearance of these cytokines in patients with CKD [25]. Therefore, future studies should investigate whether the relationships of TNF- $\alpha$ and IL- 6 with proteinuria are causal.

The current study is noteworthy because it reports that TNF- $\alpha$ and IL-6, but not CRP, are significantly associated with the prevalence and severity of CKD, independent of established risk factors, history of CVD, and use of antihypertensive, antidiabetic, and lipid-lowering agents, as well as aspirin. Careful measures of study exposure and outcome variables in this study allowed for precise estimation of the association. In addition, controls were selected from the community, which should reduce potential selection bias. Furthermore, the study participants included a racially diverse group with variable degrees of renal function and urine albumin excretion. Potential limitations of this study should be noted. First, this study cannot establish a temporal relationship or make causality inferences due to its cross-sectional, observational nature. Second, the study included a single measurement of the proinflammatory cytokines, which may not represent average levels of these biomarkers over time. However, patients with acute kidney injury were excluded from the present study. In addition, serum creatinine-based eGFR was used to define kidney function in our study. The use of cystatin C-based or cystatin- and creatininebased eGFR might provide a better assessment of kidney function regarding its predictive value for the risks of death and ESRD [26]. Finally, we were not able to analyze the association between inflammatory markers and subtype of CKD by different causes because renal biopsy data were not available in our study.

\section{Conclusions}

Our study findings suggest that TNF- $\alpha$ and IL-6, but not CRP, are associated with the prevalence and severity of CKD independent of established CKD risk factors, history of CVD, and use of antihypertensive, antidiabetic, and lipid-lowering agents and aspirin. Further studies are warranted to investigate the role of inflammatory biomarkers in the etiology of CKD and their predictive value for advanced CVD and ESRD events among patients with CKD.

\section{Abbreviations \\ BP: Blood pressure; BMI: Body-mass index; CKD: Chronic kidney disease; CRP: C-reactive protein; CV: Coefficient of variation; CVD: Cardiovascular disease; eGFR: Estimated glomerular filtration rate; ESRD: End-stage renal disease; IL-6: Interleukin-6; TNF-a: Tumor necrosis factor-alpha.}

\section{Competing interests}

The authors declare that they have no competing interests.

\section{Authors' contributions}

$B T L$ and FAA participated in interpretation of the data and drafting of the manuscript. LLH, NR, VB, and EES participated in the design of the study and coordination. FJT and KS helped in patient recruitment and data collection. CSC and YL performed the statistical analysis. JH and JC conceived of the study, participated in the design of the study, supervision of the study, and interpretation of the data, and drafted the manuscript. JC obtained research funding for the study. All authors read and approved the final manuscript.

\section{Acknowledgements}

The authors would like to express their appreciation to all study staff for their assistance in this project. In addition, we would like to thank Ms. Katherine Obst for her editorial assistance.

\section{Funding}

This study was supported by research grants (P20-RR017659 and P30-GM103337) from the National Center for Research Resources, National Institutes of Health, Bethesda, MD.

\section{Author details}

${ }^{1}$ Department of Medicine, Tulane University School of Medicine, New Orleans, LA, USA. ${ }^{2}$ Hypertension and Renal Center of Excellence, Tulane University School of Medicine, New Orleans, LA, USA. ${ }^{3}$ Southeast Louisiana Veterans Health Care System, New Orleans, LA, USA. ${ }^{4}$ Department of Epidemiology, Tulane University School of Public Health and Tropical Medicine, New Orleans, LA, USA. ${ }^{5}$ Department of Laboratory Medicine, Children's Hospital, Harvard School of Medicine, Boston, MA, USA.

Received: 20 November 2014 Accepted: 20 May 2015

Published online: 30 May 2015

\section{References}

1. Levey AS, Coresh J. Chronic kidney disease. Lancet. 2012;379:165-80.

2. Weiner DE, Tighiouart H, Elsayed EF, Griffith JL, Salem DN, Levey AS, et al. Inflammation and cardiovascular events in individuals with and without chronic kidney disease. Kidney Int. 2008;73:1406-12.

3. Bergstrom JHO, Lindholm B, Qureshi AR. C-reactive protein as predictor for serum albumin and mortality in hemodialysis. J Am Soc Nephrol. 1995;6:573-7.

4. Zimmermann J, Herlinger S, Pruy A, Metzger T, Wanner C. Inflammation enhances cardiovascular risk and mortality in hemodialysis patients. Kidney Int. 1999;55:648-58.

5. Iseki K, Tozawa M, Yoshi S, Fukiyama K. Serum C-reactive protein and risk of death in chronic dialysis patients. Nephrol Dial Transplant. 1999;14:1956-60.

6. Yeun JY, Levine RA, Mantadilok V, Kaysen GA. C-reactive protein predicts all-cause and cardiovascular mortality in hemodialysis patients. Am J Kidney Dis. 2000;35:469-76.

7. Noh H, Lee SW, Kang SW, Shin SK, Choi KH, Lee HY, et al. Serum C-reactive protein: a predictor of mortality in continuous ambulatory peritoneal dialysis patients. Perit Dial Int. 1998;18:387-94.

8. Feghali CA, Wright TM. Cytokines in acute and chronic inflammation. Front Biosci. 1997;2:d12-26.

9. Ridker PM, Rifai N, Pfeffer M, Sacks F, Lepage S, Braunwald E. Elevation of tumor necrosis factor-alpha and increased risk of recurrent coronary events after myocardial infarction. Circulation. 2000;101:2149-53.

10. Ridker PM, Rifai N, Stampfer MJ, Hennekens CH. Plasma concentration of interleukin-6 and the risk of future myocardial infarction among apparently healthy men. Circulation. 2000;101:1767-72.

11. Barreto DV, Barreto FC, Liabeuf S, Temmar M, Lemke HD, Tribouilloy C, et al. Plasma interleukin-6 is independently associated with mortality in both hemodialysis and pre-dialysis patients with chronic kidney disease. Kidney Int. 2010;77:550-6.

12. Pecoits-Filho R, Bárány $P$, Lindholm $B$, Heimbürger $\mathrm{O}$, Stenvinkel $P$. Interleukin-6 is an independent predictor of mortality in patients starting dialysis treatment. Nephrol Dial Transplant. 2002;17:1684-8.

13. Gupta J, Mitra N, Kanetsky PA, Devaney J, Wing MR, Reilly M, et al. Association between albuminuria, kidney function, and inflammatory biomarker profile in CKD in CRIC. Clin J Am Soc Nephrol. 2012;7:1938-46.

14. Upadhyay A, Larson MG, Guo CY, Vasan RS, Lipinska I, O'Donnell CJ, et al. Inflammation, kidney function and albuminuria in the Framingham Offspring cohort. Nephrol Dial Transplant. 2011;26:920-6.

15. Pickering TG, Hall JE, Appel LJ, Falkner BE, Graves J, Hill MN, et al. Recommendations for blood pressure measurement in humans and experimental animals: part 1: blood pressure measurement in humans: a statement for professionals from the Subcommittee of Professional and 
Public Education of the American Heart Association Council on High Blood Pressure Research. Circulation. 2005;111:697-716.

16. Verbraecken J, Van de Heyning P, De Backer W, Van Gaal L. Body surface area in normal-weight, overweight, and obese adults. A comparison study. Metabolism. 2006;55:515-24.

17. Levey AS, Coresh J, Greene T, Stevens LA, Zhang YL, Hendriksen S, et al. Using standardized serum creatinine values in the modification of diet in renal disease study equation for estimating glomerular filtration rate. Ann Intern Med. 2006;145:247-54.

18. McGreevy KM, Lipsitz SR, Linder JA, Rimm E, Hoel DG. Using median regression to obtain adjusted estimates of central tendency for skewed laboratory and epidemiologic data. Clin Chem. 2009;55:165-9.

19. Ridker PM. High-sensitivity C-reactive protein: potential adjunct for global risk assessment in the primary prevention of cardiovascular disease. Circulation. 2001;103:1813-8

20. Keller C, Katz R, Cushman M, Fried LF, Shlipak M. Association of kidney function with inflammatory and procoagulant markers in a diverse cohort: a cross-sectional analysis from the Multi-Ethnic Study of Atherosclerosis (MESA). BMC Nephrol. 2008;9:9.

21. Muntner P, Hamm LL, Kusek JW, Chen J, Whelton PK, He J. The prevalence of nontraditional risk factors for coronary heart disease in patients with chronic kidney disease. Ann Intern Med. 2004;140:9-17.

22. Shlipak MG, Fried LF, Crump C, Bleyer AJ, Manolio TA, Tracy RP, et al. Elevations of inflammatory and procoagulant biomarkers in elderly persons with renal insufficiency. Circulation. 2003;107:87-92.

23. Shankar A, Sun L, Klein BE, Lee KE, Muntner P, Nieto FJ, et al. Markers of inflammation predict the long-term risk of developing chronic kidney disease: a population-based cohort study. Kidney Int. 2011;80:1231-8.

24. Sarnak MJ, Poindexter A, Wang SR, Beck GJ, Kusek JW, Marcovina SM, et al. Serum C-reactive protein and leptin as predictors of kidney disease progression in the Modification of Diet in Renal Disease Study. Kidney Int. 2002;62:2208-15.

25. Bemelmans $\mathbf{M H}$, Gouma DJ, Buurman WA. Influence of nephrectomy on tumor necrosis factor clearance in a murine model. J Immunol. 1993;150:2007-17.

26. Shlipak MG, Matsushita K, Ärnlöv J, Inker LA, Katz R, Polkinghorne KR, et al. CKD Prognosis Consortium: Cystatin C versus creatinine in determining risk based on kidney function. N Engl J Med. 2013;369:932-43.

\section{Submit your next manuscript to BioMed Central and take full advantage of:}

- Convenient online submission

- Thorough peer review

- No space constraints or color figure charges

- Immediate publication on acceptance

- Inclusion in PubMed, CAS, Scopus and Google Scholar

- Research which is freely available for redistribution 